\title{
Benedetta Papasogli, La mémoire du cœur au XVII siècle
}

\author{
Daniela Dalla Valle
}

\section{(2) OpenEdition \\ Journals}

\section{Edizione digitale}

URL: http://journals.openedition.org/studifrancesi/7550

DOI: $10.4000 /$ studifrancesi. 7550

ISSN: 2421-5856

\section{Editore}

Rosenberg \& Sellier

\section{Edizione cartacea}

Data di pubblicazione: 1 décembre 2009

Paginazione: 618

ISSN: 0039-2944

\section{Notizia bibliografica digitale}

Daniela Dalla Valle, «Benedetta Papasogli, La mémoire du cœur au xvı" siècle», Studi Francesi [Online], 159 (LIII | III) | 2009, online dal 30 novembre 2015, consultato il 08 janvier 2021. URL: http:// journals.openedition.org/studifrancesi/7550 ; DOI: https://doi.org/10.4000/studifrancesi.7550

Questo documento è stato generato automaticamente il 8 janvier 2021.

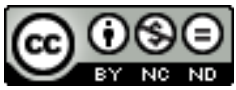

Studi Francesi è distribuita con Licenza Creative Commons Attribuzione - Non commerciale - Non opere derivate 4.0 Internazionale. 


\title{
Benedetta Papasogli, La mémoire du cour au XVII siècle
}

\author{
Daniela Dalla Valle
}

\section{NOTIZIA}

BENEDETTA PAPASOGLI, La mémoire du cœur au XVII siècle, Paris, Champion, 2008, pp. 418.

1 Benedetta Papasogli è ormai riconosciuta come una delle migliori specialiste della morale classica e della letteratura francese spirituale nel XVII secolo, e da vari anni si dedica all'analisi della problematica della memoria, in particolare nel Seicento, ma con intensi contatti con altri momenti e autori a noi più prossimi, come Rousseau, Chateubriand, Proust. Il volume che qui segnaliamo, uscito da Champion, è la rielaborazione di un lungo e appassionante periodo di ricerche dedicate al problema della memoria, la più misteriosa all'interno della triade delle "puissances de l'âme» intelletto, memoria, volontà. Il testo rielabora il bel libro Volti della memoria nel "grand siècle" e oltre (Roma, Bulzoni, 2000), per cui rinviamo alla recensione di Jean-Pierre Collinet, uscita su "Studi Francesi" (135, sett.-dic. 2001, pp. 599-600); a questo volume sono stati aggiunti numerosi studi e comunicazioni, pubblicati soprattutto in Francia negli anni successivi al 2000. D'altronde, lo stesso volume Volti della memoria si presentava già come un ampliamento e un'estensione di alcuni articoli prima pubblicati. Abbiamo voluto ricordare questo lungo passaggio, per sottolineare la ricchezza e l'approfondimento costante della ricerca della Papasogli su questo argomento. Una Introduction (pp. 7-27) presenta il volume in questione che qui segnaliamo: in essa è segnalato il problema critico affrontato, il contrasto e il confronto fra le due nozioni di "memoria" - quella «artificielle qui préside aux mnémotechniques» e quella "affective»; si riferisce alle ricerche sull'una e l'altra memoria nell'arco cronologico, sottolineando una sorta di "buco", un «trou de mémoire» nel XVII secolo; e segnala poi il progetto di questo volume, che consiste appunto nello studio della memoria in questo periodo apparentemente privo di 
riflessioni al riguardo; descrive poi come il volume sarà composto: tre parti, la prima sulla Littérature morale, la seconda sulla Littérature spirituelle, la terza su una serie di Échos, colti e suggeriti in vari momenti della letteratura secentesca («Roman et nouvelle», Cinna, La Princesse de Clèves, Racine, Fénelon). Per concludere poi con un'appendice che prolunga il discorso nella Vie de Rancé di Chateaubriand.

2 Il volume dunque si propone come la conclusione brillante di una lunga analisi, ricchissima di riferimenti a testi illustri e meno illustri, assolutamente documentata con puntuali rinvii agli studi bibliografici sull'argomento. 